\title{
Dynamin II interacts with the cadherin- and occludin-based protein complexes at the blood-testis barrier in adult rat testes
}

\author{
Pearl P Y Lie*, Weiliang Xia*, Claire Q F Wang*, Dolores D Mruk*, Helen H N Yan, Ching-hang Wong, \\ Will M Lee ${ }^{1}$ and $C$ Yan Cheng
}

Center for Biomedical Research, Population Council, 1230 York Avenue, New York, New York 10021, USA

${ }^{1}$ Department of Zoology, University of Hong Kong, Hong Kong, China

(Requests for offprints should be addressed to C Yan Cheng; Email: y-cheng@popcbr.rockefeller.edu)

*(P P Y Lie, W Xia, C Q F Wang and D D Mruk contributed equally to the completion of this work)

\begin{abstract}
In adult rat testes, blood-testis barrier (BTB) restructuring facilitates the migration of preleptotene spermatocytes from the basal to the adluminal compartment that occurs at stage VIII of the epithelial cycle. Structural proteins at the BTB must utilize an efficient mechanism (e.g. endocytosis) to facilitate its transient 'opening'. Dynamin II, a large GTPase known to be involved in endocytosis, was shown to be a product of Sertoli and germ cells in the testis. It was also localized to the BTB, as well as the apical ectoplasmic specialization (apical ES), during virtually all stages of the epithelial cycle. By co-immunoprecipitation, dynamin II was shown to associate with occludin, $\mathrm{N}$-cadherin, zonula occludens-1 (ZO-1), $\beta$-catenin, junctional adhesion molecule-A, and $\mathrm{p} 130 \mathrm{Cas}$, but not nectin-3. An in vivo model in rats previously characterized for studying adherens junction (AJ) dynamics in the testes by adjudin (formerly called AF-2364, 1-(2,4-dichlorobenzyl)-1H-indazole-3-carhohydrizide) treatment was used in our studies. At the time of germ cell loss from the seminiferous epithelium as a result of adjudin-induced AJ restructuring without disrupting the
\end{abstract}

BTB integrity, a significant decline in the steady-state dynamin II protein level was detected. This change was associated with a concomitant increase in the levels of two protein complexes at the BTB, namely occludin/ZO-1 and $\mathrm{N}$-cadherin/ $\beta$-catenin. Interestingly, these changes were also accompanied by a significant increase in the structural interaction of dynamin II with $\beta$-catenin and ZO-1. $\beta$-Catenin and $\mathrm{ZO}-1$ are adaptors that structurally link the cadherin- and occludin-based protein complexes together at the BTB in an 'engaged' state to reinforce the barrier function in normal testes. However, $\beta$-catenin and $\mathrm{ZO}-1$ were 'disengaged' from each other but bound to dynamin II during adjudin-induced $\mathrm{AJ}$ restructuring in the testis. The data reported herein suggest that dynamin II may assist the 'disengagement' of $\beta$-catenin from $\mathrm{ZO}-1$ during $\mathrm{BTB}$ restructuring. Thus, this may permit the occludin/ZO-1 complexes to maintain the BTB integrity when the cadherin/catenin complexes are dissociated to facilitate germ cell movement.

Journal of Endocrinology (2006) 191, 571-586

\section{Introduction}

In adult rat testes, the blood-testis barrier (BTB) is composed of co-existing tight (TJ) and adherens junctions (AJ; e.g. basal ectoplasmic specialization (basal ES), an actin-based testisspecific AJ type) between adjacent Sertoli cells (Vogl et al. 1991, 2000, Cheng \& Mruk 2002, Toyama et al. 2003, Mruk $\&$ Cheng 2004). It also physically divides the seminiferous epithelium into the basal and adluminal compartments. While these specialized junctions that constitute the BTB confer one of the tightest barriers in mammals, the BTB is a highly dynamic cellular structure. For instance, during stage VIII of the epithelial cycle in adult rat testes, preleptotene spermatocytes must translocate across the BTB (Russell 1977), entering the apical compartment for further development, and differentiating into pachytene spermatocytes. As such, the BTB must 'disassemble' (or open?) to facilitate preleptotene spermatocyte movement. Thus, it is conceivable that extensive turnover of proteins is occurring at the BTB during spermatogenesis. Five different classes of protein complexes have been found at the BTB. These include occludins/zonula occludens-1 (ZO-1), junctional adhesion molecules (JAMs)/ ZO-1, claudins/ZO-1, nectins/afadins, and cadherins/catenins (Wong \& Cheng 2005, Xia et al. 2005a), although some of these are also found in the apical ectoplasmic specialization (apical ES) at the Sertoli cell-elongating spermatid interface (e.g. nectins/afadins and cadherins/catenins; Wine \& Chapin 1999, Chapin et al. 2001, Johnson \& Boekelheide 2002, Lee et al. 2003, Sluka et al. 2006). The interaction of the integral membrane proteins (such as occludins and cadherins) and 
their adaptors (such as ZO-1 for occludins and catenins for $\mathrm{N}$-cadherin) is regulated by protein/lipid kinases and phosphatases (Mruk \& Cheng 2004). Recent studies have illustrated that the dynamic nature of the BTB is regulated, at least in part, by the engagement and the disengagement of integral membrane proteins and their peripheral adaptors of adjacent Sertoli cells (Yan \& Cheng 2005). For instance, it was shown that during extensive AJ restructuring that facilitated germ cell movement, there was a loss in association between catenins and ZO-1, the corresponding adaptors of cadherins and occludin respectively (Yan \& Cheng 2005). Thus, this disengaged the interacting cadherins and occludins at the $\mathrm{BTB}$, facilitating germ cell movement while the occludinZO-1 complexes continued to maintain the BTB integrity (Yan \& Cheng 2005). However, the molecule(s) that facilitates such changes in protein-protein interactions, likely via transient protein 'internalization' or 'reshuffling', has yet to be identified. Recent studies have shown that GTPases are the crucial players of protein trafficking (Takai et al. 2001, Lui et al. 2003a, Mruk et al. 2005). As such, we sought to investigate the role of dynamin in such events.

Dynamin is a family of large GTPases implicated in the formation of nascent vesicles during both endocytosis and the secretory process (for reviews, see McNiven et al. 2000, Sever et al. 2000b, Hinshaw 2006, Kruchten \& McNiven 2006, Robinet et al. 2006). Dynamin is known to play an important role in the internalization of integral membrane proteins (e.g. occludin and N-cadherin) in multiple epithelia (Orth \& McNiven 2003) and serves as pinchase-like mechanoenzyme to facilitate the formation of endocytic vesicles by severing nascent endocytic pits from the plasma membrane (Thompson \& McNiven 2001, Cao et al. 2003). The best studied function of the dynamin family of proteins is the promotion of vesicle fission during clathrin-mediated endocytosis (Sever et al. 2000a, Hinshaw 2006, Kruchten \& McNiven 2006). Other functions, such as membrane tubulation and phagosome formation, have also been ascribed to dynamin (Orth \& McNiven 2003). Members of the dynamin family include three classical dynamins, namely dynamins I, II, and III, and also dynamin-like proteins. Dynamin I is a neural specific isoform pertinent to synaptic vesicle recycling. Dynamin II is ubiquitously expressed in all eukaryotic cells, and it has recently been identified in the testis (Iguchi et al. 2002). It is crucial for the endocytosis of integral membrane proteins (McNiven et al. 2000, Sever et al. 2000b). Dynamin III is a testis-specific isoform (Kamitani et al. 2002). A recent study has reported that dynamin $\mathrm{I}$ is absent in the testis, while the other two isoforms are highly expressed (Kamitani et al. 2002). Nonetheless, the functions of dynamins in the testis remain to be elucidated. It was postulated that dynamins may play a role in nutrient provision to germ cells via endocytosis (Kamitani et al. 2002). In this report, we have examined the possible role of dynamin II in BTB dynamics via its specific interactions with the occludin/ ZO-1 and the $\mathrm{N}$-cadherin/ $\beta$-catenin protein complexes at the BTB.

\section{Materials and Methods}

\section{Animals}

Male Sprague-Dawley rats ( 270-300 g body weight) were purchased from Charles River Laboratories (Kingston, NY, USA). The use of animals in this study was approved by the Rockefeller University Animal Care and Use Committee with Protocol Numbers 03017 and 06018.

\section{Primary Sertoli and germ cell cultures}

Sertoli and germ cells were isolated from the testes of 20- and 90-day-old rats respectively, as detailed elsewhere (Mruk et al. 1997, 2003). In short, Sertoli cells were cultured at a density of $5 \times 10^{5}$ cells $/ \mathrm{cm}^{2}$ on $100 \mathrm{~mm}$ dishes in F12/DMEM (Ham's F12 Nutrient Mixture: Dulbecco's Modified Eagle's Medium, $\mathrm{V} / \mathrm{V}, 1: 1)$ at $35{ }^{\circ} \mathrm{C}$ in a humidified atmosphere of $95 \%$ air $/ 5 \% \mathrm{CO}_{2}$ with supplements (Mruk et al. 1997). On day 2, these cultures were subjected to a hypotonic treatment (10 mM Tris, $\mathrm{pH} 7 \cdot 4$ at $22{ }^{\circ} \mathrm{C}$ for $2 \mathrm{~min}$; Galdieri et al. 1981) to lyse residual germ cells, and cultures were terminated on day 4 for lysate preparation and RNA extraction as described (Mruk et al. 2003). On the other hand, total germ cells were isolated from adult rat testes and used for lysate preparation and RNA extraction within $6 \mathrm{~h}$ as described (Aravindan et al. 1996). Both primary cultures had negligible contamination of other cell types, and this has been vigorously characterized by RT-PCR, immunoblotting, light and electron microscopy as reported earlier from this laboratory (Siu et al. 2005).

\section{Isolation of seminiferous tubules}

Seminiferous tubules were isolated from adult rat testes ( 300-350 g body weight) as described (Zwain \& Cheng 1994). Tubules were incubated in F12/DMEM containing insulin $(20 \mu \mathrm{g} / \mathrm{ml})$, human transferrin $(20 \mu \mathrm{g} / \mathrm{ml})$, gentamicin $(100 \mu \mathrm{g} / \mathrm{ml})$, and penicillin $(100 \mathrm{IU} / \mathrm{ml})$ at $35^{\circ} \mathrm{C}$ for about $6 \mathrm{~h}$ before they were harvested for lysate preparation. The tubules used in this report had negligible contamination of Leydig cells since these tubules failed to respond to hCG $(10 \mathrm{ng} / \mathrm{ml})$ treatment when the level of testosterone was quantified as described (Zwain \& Cheng 1994).

\section{Treatment of rats with adjudin to induce junction restructuring}

Adult rats ( $\sim 270-300 \mathrm{~g}$ body weight, b.w.; $n=3-5$ for each time point) were treated with adjudin (1-(2,4-dichlorobenzyl)-1H-indazole-3-carbohydrazide, formerly called AF2364, a molecule that induces adherens junction disruption in testis) via gavage at $50 \mathrm{mg} / \mathrm{kg} \mathrm{b}$.w. at time 0 . The treated rats were killed after 1, 4, $8 \mathrm{~h}$ and 1, 4, 7, and 14 days thereafter. Adjudin was suspended in methylcellulose $(0 \cdot 25 \%$ $(\mathrm{w} / \mathrm{v})$ in sterile water) as a stock solution of $20 \mathrm{mg} / \mathrm{ml}$. This treatment is known to induce extensive AJ restructuring in the seminiferous epithelium at the Sertoli-germ cell interface, 
most notably between Sertoli cells and elongating/elongate spermatids, followed by round spermatids and spermatocytes, but not spermatogonia (Chen et al. 2003, Cheng et al. 2005). However, the BTB integrity has been observed to be unaffected by day 15 following adjudin treatment (Mruk \& Cheng 2004, Cheng et al. 2005).

\section{Sample preparation}

Lysates were obtained by treating Sertoli cells, germ cells, testes, or seminiferous tubules with a lysis buffer $(50 \mathrm{mM}$ Tris $-\mathrm{HCl}$, $0 \cdot 15 \mathrm{M} \mathrm{NaCl}, 1 \%$ Nonidet P-40 (v/v), $1 \mathrm{mM}$ EGTA, $1 \mathrm{mM}$ phenylmethylsulphonyl fluoride, $1 \mu \mathrm{g} / \mathrm{ml}$ leupeptin, $1 \mu \mathrm{g} / \mathrm{ml}$ aprotinin, and $1 \mathrm{mM}$ sodium orthovanadate), followed by sonication and centrifugation at $13000 \mathrm{~g}$ for $10 \mathrm{~min}$ to obtain the clear supernatant. The use of EGTA instead of EDTA in the lysis buffer as a chelating agent to block metalloprotease activity was important. Since EDTA was shown to chelate with vanadate (Crans et al. 1989, Huyer et al. 1997, Siu et al. 2005), it would reduce the level of free vanadate included in the buffer that blocked the activity of protein-tyrosine phosphatases (PTP) in lysates. If PTP activity remained unchecked, this would affect the phosphorylation status of component proteins at the BTB, adversely affecting protein-protein interactions in the samples to be analyzed. Protein concentration was estimated by Coomassie blue dye-binding assay using BSA as a standard (Bradford 1976).

\section{Antibodies}

Commercially obtained antibodies listed in Table 1 were used for immunoblot analysis, immunohistochemistry, fluorescent microscopy, and co-immunoprecipitation. All three antidynamin antibodies used in our study cross-reacted with dynamins I and II, but since dynamin I is absent in the testis (Kamitani et al. 2002), dynamin signals reported herein were only from dynamin II.

\section{Immunoblot analysis}

One-hundred micrograms protein from each sample within an experimental group were resolved by SDS-PAGE using $7 \cdot 5,10$, or $12 \cdot 5 \%$ T SDS-polyacrylamide gels under reducing conditions, depending on the relative molecular mass of the target proteins. Proteins were then transferred onto nitrocellulose membranes for immunoblot analysis as described earlier (Mruk et al. 2003). Commercially obtained antibodies against different target proteins are listed in Table 1. All immunoblots were densitometrically scanned using SPSS SigmaGel software (version 1.05) from SPSS Inc. (Chicago, IL, USA) and normalized against the level of $\beta$-actin to confirm equal protein loading.

\section{Immunohistochemistry and fluorescent microscopy}

For both immunohistochemistry and fluorescent microscopy experiments, the rabbit anti-dynamin antibodies from Cell Signaling Technology (Beverly, CA, USA) and Abcam, Inc. (Cambridge, MA, USA; see Table 1) were used, whereas the mouse antibody from BD Transduction Laboratories (San Jose CA, USA) failed to work in these studies. While both rabbit antibodies yielded specific staining in the seminiferous epithelium in preliminary studies, the antibody from Abcam produced much better resolution and at a significantly lower working dilution $(1: 300$ vs $1: 75$, see Table 1). As such, all reported results regarding dynamin were from experiments carried out with the antibody from Abcam. Immunohistochemistry was performed as described earlier (Siu et al. 2005). In short, frozen testes were embedded in optimal cutting temperature (OCT; Sakura Finetek USA Inc., Torrance, CA, USA) compound, and sectioned to $\sim 6-8 \mu \mathrm{m}$ thickness in a cryostat at $-20{ }^{\circ} \mathrm{C}$. Cross-sections from different testes within an experimental group were mounted onto one to two poly-L-lysine-coated slides

Table 1 The sources and working dilutions of antibodies used for different studies in this report

\section{Vendor}

Santa Cruz Biotechnologies (Santa Cruz, CA, USA)

Zymed Laboratories Inc. (South San Francisco, CA, USA)

BD Transduction Laboratories (San Diego, CA, USA) Cell Signaling Technology (Beverly, CA, USA)

Abcam, Inc. (Cambridge, MA, USA)

\begin{tabular}{|c|c|c|c|}
\hline Antibody & Source $^{a}$ & Cat no. & Lot no. \\
\hline N-Cadherin & Rabbit & sc-7939 & J1502 \\
\hline$\beta$-Catenin & Rabbit & sc-7199 & E1105 \\
\hline$\beta$-Actin & Goat & sc-1616 & G1905 \\
\hline Occludin & Rabbit & $71-1500$ & 50393483 \\
\hline ZO-1 & Rabbit & $61-7300$ & 50799336 \\
\hline ZO-1-FITC & Mouse & $33-9111$ & 30879018 \\
\hline $\mathrm{N}$-Cadherin & Mouse & $33-3900$ & 30778768 \\
\hline JAM-A & Rabbit & $36-1700$ & 30979650 \\
\hline Dynamin & Mouse & 610245 & 0000085934 \\
\hline Dynamin & Rabbit & 2342 & 1 \\
\hline Dynamin & Rabbit & Ab 3457-100 & 156340 \\
\hline
\end{tabular}

\begin{tabular}{lll} 
Usage $^{b}$ & & $\begin{array}{l}\text { Working } \\
\text { dilution }\end{array}$ \\
\cline { 1 - 1 } & & \\
IP, IB & & $1: 100$ \\
IP, IB & & $1: 100$ \\
IP, IB & & $1: 100$ \\
IP, IB, IF & & $1: 100$ \\
IP, IB & & $1: 100$ \\
IF & & $1: 100$ \\
IF & & $2 \cdot 5 \mu g / \mathrm{mI}$ \\
IF, IB & & $1: 250$ \\
IB & $1: 1000$ \\
IB, IHC, IF & $1: 75$ \\
IHC, IF & $1: 300$
\end{tabular}

${ }^{\mathrm{a}} \mathrm{All}$ rabbit antibodies were polyclonal and mouse antibodies were monoclonal.

bIP, immunoprecipitation; IB, immunoblotting; IF, immunofluorescent microscopy; IHC, immunohistochemistry.

${ }^{\mathrm{c}}$ The listed dilutions are the optimal working dilutions based on different preliminary experiments at different dilutions over a period of 18 months for the experiments reported herein. 
(Polysciences Inc., Warrington, PA, USA; with approximately two to three sections per glass slide) and processed simultaneously in an experimental session to avoid interexperimental variations. Color development was carried out with Histostain-SP kit (Zymed, South San Francisco, CA, USA). In preliminary experiments, paraffin sections were also tested for immunohistochemistry studies. However, none of the three anti-dynamin antibodies from different vendors (see Table 1) yielded satisfactory results. Therefore, data presented here were all obtained from the use of frozen sections. Immunofluorescent microscopy was performed as described earlier (Lee et al. 2003, Siu et al. 2005) using either Cy3 or FITC-conjugated secondary antibodies (see Table 1). All micrographs were acquired using an Olympus BX40 microscope equipped with UPlanF1 fluorescent optics and an Olympus DP70 Digital Camera. Images were captured using QCapture Suite Imaging Software (version 2.56; Quantitative Imaging Corp., Burnaby, BC, Canada). Results from morphology studies reported in this paper were representative data from four to six different experiments performed by two different investigators, which yielded similar observations.

\section{Co-immunoprecipitation (co-IP)}

Co-IP was performed essentially as described earlier (Wong et al. 2005, Yan \& Cheng 2005). In brief, sample lysates containing $400 \mu \mathrm{g}$ protein were pre-cleared as follows to eliminate non-specific interactions between $\operatorname{IgG}$ and proteins in lysates. Samples were incubated with normal rabbit (or mouse) $\operatorname{IgG}(\sim 5 \mu \mathrm{g})$, followed by an incubation with Protein A/G PLUS Agarose $(10 \mu \mathrm{l})$, and then centrifuged to obtain the clear supernatant for subsequent Co-IP. The pre-cleared samples were then incubated with corresponding primary antibodies overnight. The immunocomplexes were immunoprecipitated by Protein A/G PLUS agarose (Santa Cruz Biotechnologies, Santa Cruz, CA, USA), extracted in SDS sample buffer, and resolved by SDS-PAGE for immunoblotting. Negative controls were included such that the precipitating antibodies were replaced by either rabbit or mouse IgG. All samples within an experimental group were processed simultaneously in a single experimental session to eliminate interexperimental variations. Each Co-IP experiment was repeated at least thrice using different batches of cell and tubule lysates.

\section{Statistical analysis}

All experiments reported herein were repeated for three to five times using different batches of cells. For in vivo experiments, at least six rats, including controls, were used for each time point. Data within an experimental group were analyzed by ANOVA, and statistical significance was estimated by Tukey's honest significant test using GBSTAT (version 7.0) software package from Dynamic Microsystem Inc. (Silver Spring, MD, USA).

\section{Results}

Localization and cellular association of dynamin II in adult rat testes

Figure $1 \mathrm{~A}-\mathrm{F}$ illustrates the representative results of an immunohistochemistry experiment performed on frozen sections of adult rat testes by incubating with the rabbit antidynamin antibody. Specific signals from dynamin II were detected, as explained in Materials and Methods. Dynamin II appears as reddish-brown precipitate localized mostly to the apical ES with strongest staining in stages VII-VIII tubules (see Fig. 1A). Figure $1 \mathrm{~B}$ shows a normal rat testis section incubated with rabbit IgG in place of the primary antibody, illustrating the antibody specificity. Since only very weak background staining was found in the interstitium. The strongest dynamin II staining was detected in an early stage VIII tubule as shown in Fig. 1C. Figure 1D is a magnified view of the boxed area in Fig. 1C, demonstrating the dynamin II staining on the convex surface of the heads of elongating spermatids, consistent with its localization at the apical ES. Weak but still discernible dynamin II staining was found at the apical ES site of elongating spermatids in stages Vand $\mathrm{X}$ tubules (see Fig. $1 \mathrm{E}$ and $\mathrm{F}$ vs $\mathrm{C}$ and D). Furthermore, dynamin II was detected in the basal compartment of the seminiferous epithelium, localizing at the $\mathrm{BTB}$ in virtually all tubules examined (see Fig. 1A and $\mathrm{C}-\mathrm{F}$ ). Dynamin II was also found to be associated with round spermatids, spermatocytes, and spermatogonia in stages VIIVIII tubules, though signals attenuated in stages $\mathrm{V}$ and $\mathrm{X}$ (see Fig. 1C-F). This was suggestive of its localization at the desmosome-like junctions, since apical ES is absent at the interface between these germ and Sertoli cells in the epithelium. The specificity of this antibody from Abcam (Table 1) was further verified by immunoblotting as shown in Fig. 1G. Only one prominent band with an electrophoretic mobility corresponding to the apparent relative molecular mass of dynamin II (100 kDa) was detected in the lysates of seminiferous tubules and germ cells from adult rats, and Sertoli cells from 20-day-old rats. The relative expression level of dynamin II in different cellular fractions of the testis was also investigated (Fig. 1H and I). It was shown that germ cells expressed approximately three times more dynamin II than Sertoli cells (Fig. 1I). This result is consistent with an earlier report describing the relative abundance of dynamin in germ vs Sertoli cells (Kamitani et al. 2002).

\section{Co-localization of dynamin II with other target proteins at the $B T B$ and their structural association}

We next used fluorescent microscopy to examine the co-localization of dynamin II with proteins at the BTB. Figure 2A-D, E-H illustrate the co-localization of occludin and JAM-A (both are putative integral membrane proteins at the BTB) with their adaptor $\mathrm{ZO}-1$ in the seminiferous epithelium, consistent with their localization at the BTB in adult rat testes. It is worthy to note that dynamin II was 
found to be localized at the apical ES as well as the BTB (see Fig. 2I and M), which is consistent with the results of the immunohistochemistry as shown in Fig. 1A-D. Dynamin II partially co-localized with ZO-1 at the BTB (Fig. 2I-L). At the same time, its co-localization with
$\mathrm{N}$-cadherin was also observed, but the merged signal was much weaker (Fig. 2M-P). To further verify these observations, specific antibodies against different target proteins (see Table 1) were used for co-immunoprecipitation (Co-IP), and precipitable immunocomplexes were
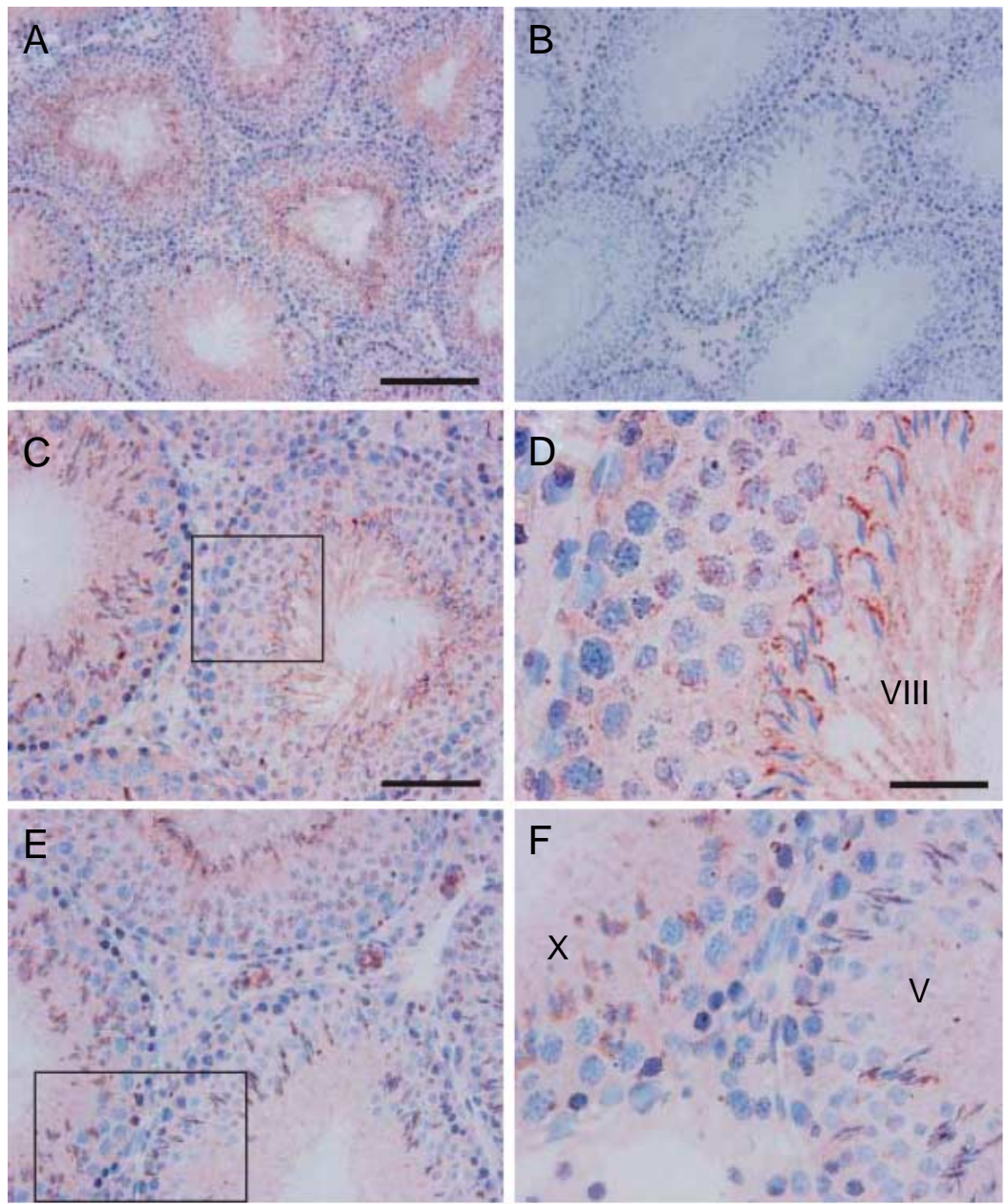

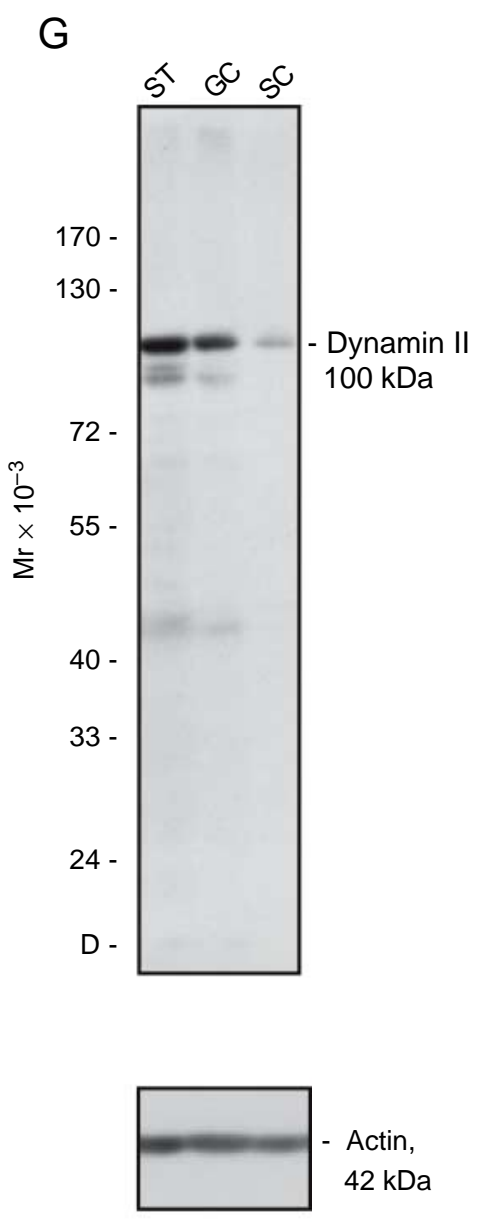

$\mathrm{H}$
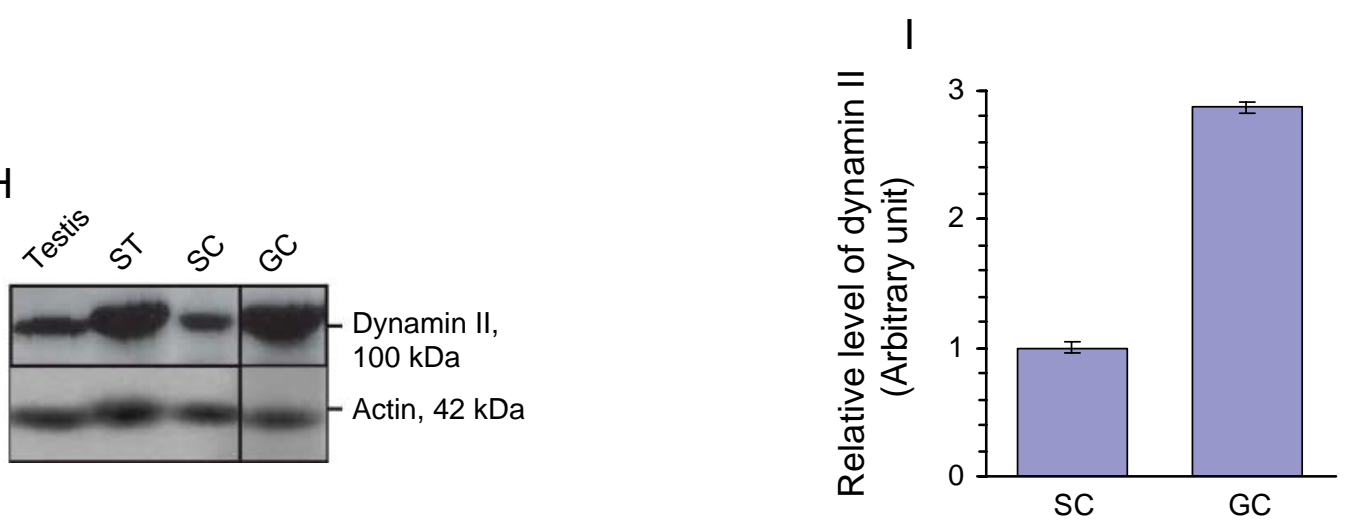

www.endocrinology-journals.org 
then probed for dynamin II by immunoblotting as shown in Fig. 2Q. It was shown that dynamin II indeed was associated with occludin, N-cadherin, ZO-1, $\beta$-catenin, JAM-A, p130Cas, and $\beta$-actin, but not nectin-3 (Fig. 2Q). These results are thus in agreement with the current knowledge that dynamins are involved in trafficking events between cell membrane and the actin network in particular internalization of integral membrane proteins (e.g. occludin and N-cadherin; Orth \& McNiven 2003).

Changes in dynamin II steady-state protein level and its cellular association in the seminiferous epithelium during adjudin-induced junction restructuring and germ cell depletion

Adjudin is known to induce germ cell depletion from the seminiferous epithelium without compromising the BTB integrity at the time of extensive anchoring junction restructuring (Mruk \& Cheng 2004, Cheng et al. 2005). The drug apparently exerts its effects at the Sertoli-germ cell interface, for instance, by disrupting the integrin/laminin protein complex at the apical ES (Siu et al. 2005). In previous mating studies, the anti-fertility effect of adjudin was not visible until the sperm reserve at the epididymides was exhausted, 3-4 weeks after treatment (Cheng et al. 2005). This observation illustrated that adjudin has no apparent toxicity to germ cells. Otherwise, the infertility effect would have been detected within 1-2 weeks since elongate/elongating spermatids were virtually depleted from the epithelium from days 4 to 14 (see Fig. 3). Therefore, this model was used to examine changes in the dynamin II protein level and its cellular association during extensive junction restructuring in the seminiferous epithelium. As shown in Fig. 3A and B, there was a trend of time-dependent decline in dynamin II protein level in testes when germ cells began to detach from the epithelium from day 1 onwards except for a mild and statistically insignificant increase in hours 1-8 post-treatment. This trend of declining dynamin II in the testis was not entirely unexpected since dynamin II is largely expressed by elongating/elongate spermatids (see Fig. 1). The data shown in Fig. 3A and B were validated by immunohistochemistry studies to visualize the distribution of dynamin II in the seminiferous epithelium during adjudin-induced germ cell loss (see Fig. 3C-F). For instance, a decline in dynamin II staining was detected in the epithelium from days 4 to 14 when elongating/elongate spermatids were being depleted from the epithelium. This event was accompanied by a loss of dynamin II at the Sertoli cell-spermatid apical ES site (Fig. 3D-F vs A). It is also worthy to note that dynamin II was still seen to be surrounding the heads of the elongate spermatids remaining in the tubule lumen (see black arrowheads in Fig. 3D-F). Interestingly, while the overall dynamin II staining in the epithelium was weak, its signals at the BTB did not appear to be diminished by day 14 when the tubules were virtually devoid of spermatids and spermatocytes. Instead, the staining intensity at the BTB was considerably higher as compared with normal testes (see Fig. 3F vs C-E).

\section{Changes in the steady-state levels of target proteins at the BTB} during junction restructuring in the seminiferous epithelium

In the same experiment during which the level of dynamin II was quantified (see Fig. 3), the steady-state levels of two known protein complexes at the BTB, namely $\mathrm{N}$-cadherin/ $\beta$-catenin and occludin/ZO-1, were also measured (Fig. 4A and B). It was found that levels of these proteins increased significantly. As some of these proteins are restricted to (e.g. occludin) or predominantly expressed by (e.g. ZO-1) Sertoli cells, their increase in protein levels shown by immunoblots might reflect changes in cellular contribution instead of an increase in de novo synthesis. For instance, as shown in Fig. 3E and F, the lysates obtained from these testes were largely

Figure 1 (A-I) A study to assess the localization of dynamin II and its cellular association in the seminiferous epithelium of adult rat testes. (A-F) Immunohistochemical localization of dynamin II using frozen sections of normal testes from adult rats ( $\sim 270-300 \mathrm{~g}$ body weight) at $\sim 90-$ 120 days of age (see Materials and Methods). Dynamin II appears as a reddish-brown precipitate. It was found in the apical ES at Sertoli cellelongating spermatid interface, as well as in the basal compartment at the BTB (A, C-F). The localization of dynamin II at the apical ES appeared to be stage specific, since the staining was more intense in stages VII-VIII tubules (see A). However, it was present at the BTB in virtually all stages of the epithelial cycle (see A, C-F). B is a control using normal rabbit IgG to substitute the primary antibody, showing very weak staining in the interstitium. This illustrates that the staining shown in A and C-F is specific to dynamin II. D and F are the magnified views of the corresponding boxed areas in the tubules shown in C and E. The micrograph shown in D has clearly illustrated that intensive dynamin II immunoreactive substances were associated with the apical ES surrounding the heads of elongate spermatids at the convex side of the head region, consistent with its localization at the apical ES (C and D). In addition to elongate spermatids, dynamin II staining was also detected at the apical ES in elongating spermatids in stages $\mathrm{V}$ and $\mathrm{X}$ tubules (see $\mathrm{E}, \mathrm{F}$ ). Furthermore, dynamin II staining could also be found in the nuclei of spermatocytes and round spermatids in stage VIII tubules (see D) but the signal was much weaker in other stages, such as V and X tubules (see F vs D). The data shown herein are the representative results of three independent experiments using testes from different rats excluding preliminary experiments using antibodies from different vendors (see Table 1). Bar in $A=90 \mu \mathrm{m}$, which applies to $B$; bar in $C=40 \mu \mathrm{m}$, which applies to $E$; bar in $D=15 \mu \mathrm{m}$, which applies to F. (G) Immunoblotting using lysates of seminiferous tubules (ST), Sertoli cells (SC), and germ cells (GC; $50 \mu$ g total protein per lane) for SDS-PAGE and probed with the anti-dynamin IgG that was used in the immunohistochemistry experiment shown in A-F. Only one prominent protein band was detected, with an electrophoretic mobility of $100 \mathrm{kDa}$ corresponding to dynamin II. This experiment illustrates the specificity of this antibody, indicating that the staining shown in A-F is specific. The lower panel shows the same blot being re-probed with an anti-actin antibody to assess equal protein loading. $(\mathrm{H})$ Semi-quantitative analysis of dynamin II in testes from adult rats, ST, SC, and GC using the corresponding protein lysates $(\sim 100 \mu$ g protein per lane) for immunoblotting (upper panel). The lower panel shows the same blot being re-probed with an anti- $\beta$-actin antibody to assess equal protein loading. (I) A histogram using data such as those shown in $\mathrm{H}$, and normalized against $\beta$-actin $(n=3)$ after densitometric scanning analysis, illustrating that the steady-state protein level of dynamin II in SC:GC is 1:3. It is noted that ST and GC were obtained from adult rats whereas SC were obtained from 20-day-old rat testes. 

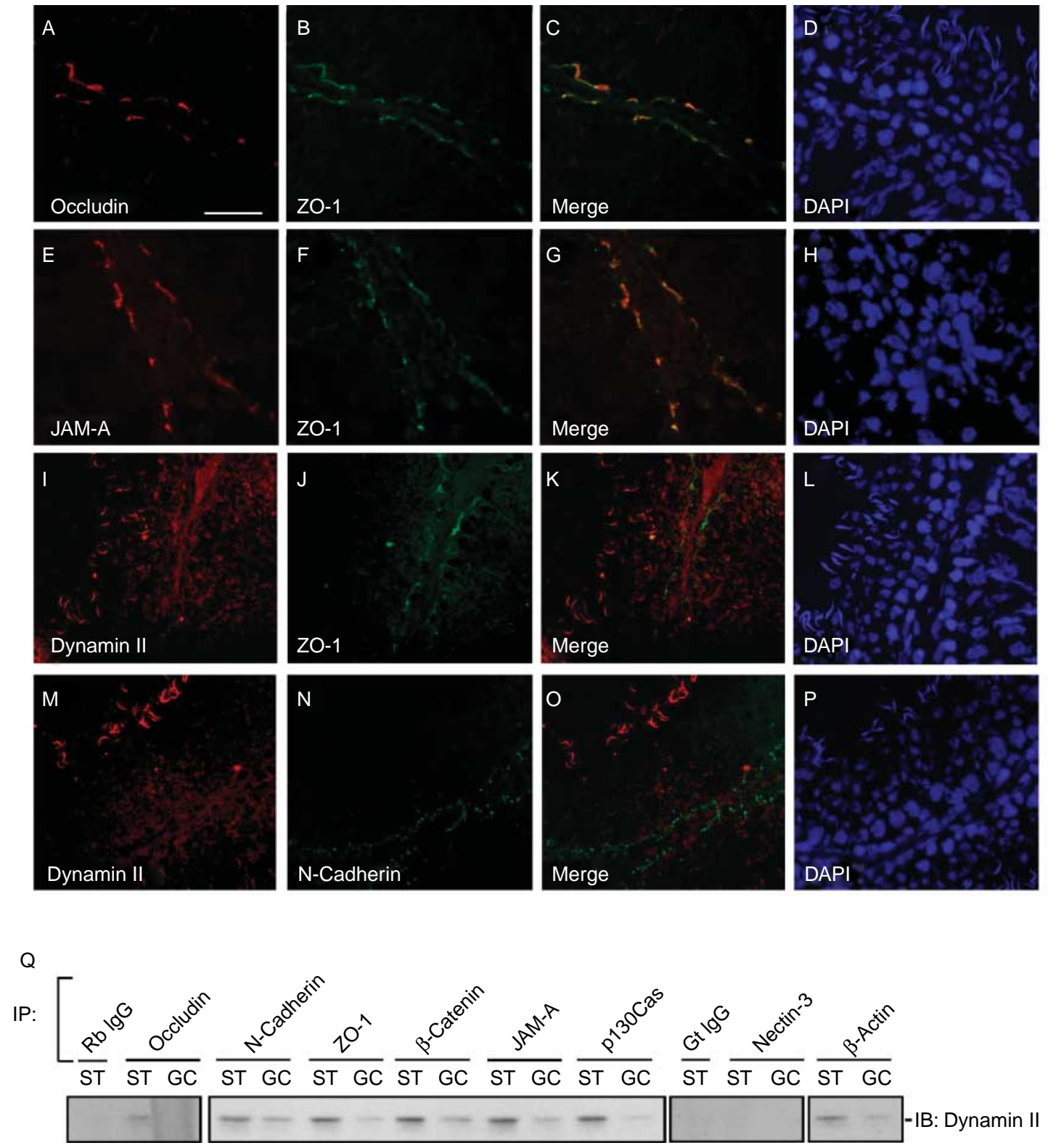

Figure 2 (A-Q) A study to assess the association of dynamin II with BTB proteins in the seminiferous epithelium by immunofluorescent microscopy (A-P) and co-immunoprecipitation (Co-IP) (Q). (A-P) Fluorescent micrographs that illustrate the co-localization of occludin and ZO-1 at the BTB (A-D), which is similar to JAM-A and ZO-1 (E-H). It is noted that Cy3 is red fluorescence and FITC is green fluorescence. Cell nuclei were stained with DAPI. Dynamin II also co-localized, at least in part, with ZO-1 (I-L); and to a lesser extent with N-cadherin (M-P), at the basal compartment consistent with its localization at the BTB; although most dynamin II fluorescence was detected at the apical ES site at the elongating/elongate spermatid-Sertoli cell interface. The results shown here are the data from a representative experiment. This experiment was repeated at least twice using sections obtained from different animals which yielded similar results. Bar in $A=60 \mu \mathrm{m}$, which applies to B-P. (Q) The results shown above were further confirmed by a Co-IP experiment. Lysates of either ST (seminiferous tubules) or GC (germ cells) from testes of adult rats were used for Co-IPas described in Materials and Methods. Negative controls are samples treated with either normal rabbit $(\mathrm{Rb})$ or goat $(\mathrm{Gt}) \operatorname{lgG}$ instead of the primary precipitating antibodies. It is worthy of note that dynamin II interacted with occludin (in lysates of ST but not GC since germ cells do not express occludin), N-cadherin, ZO- 1 , $\beta$-catenin, JAM-A, p130Cas, and $\beta$-actin, but not nectin-3. The data shown herein are the results of a representative experiment which was repeated thrice using different sets of samples that yielded similar observations. IB, immunoblot. 
A

Time after treatment of rats with adjudin (50 mg/kg b.w., by gavage)
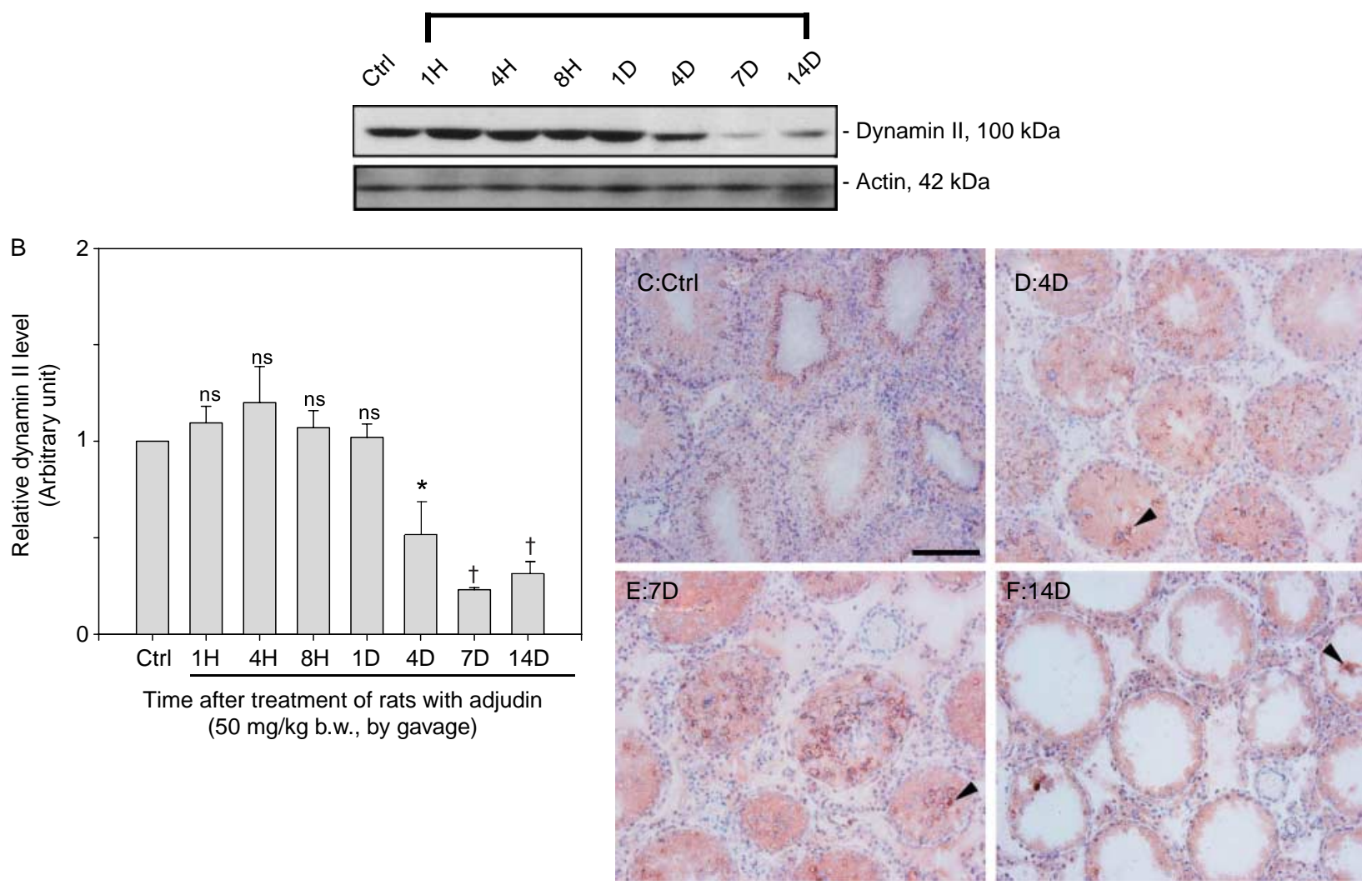

Figure 3 (A-F) Changes in the steady-state protein levels of dynamin II (A-B) and its localization (C-F) in the epithelium during adjudininduced germ cell loss. (A-B) Lysates ( $\sim 100 \mu$ g protein) obtained from testes of rats treated with a single dose of adjudin (50 mg/kg b.w., by gavage) were resolved by SDS-PAGE for immunoblottings (A). The results shown in A are summarized in the histogram shown in B with $n=4$ rats. It is noted that by day 4 when most of the germ cells were depleted from the seminiferous epithelium (see D-F vs C), a significant decline in the steady-state dynamin II protein level was detected (B), which persisted through days 7-14. ns, not significantly different by ANOVA; ${ }^{*} P<0 \cdot 05 ;{ }^{\dagger} P<0 \cdot 01$. (C-F) These micrographs are the results of an immunohistochemistry experiment using an anti-dynamin antibody (see Table 1). It should be noted that by day 4 after adjudin treatment, most of the elongating/elongate spermatids were depleted from the epithelium, and the loss of dynamin II staining was consistent with the results shown in A-B. However, some elongate spermatids remaining in the tubule lumen were still stained positive for dynamin II (see black arrowhead in D), this trend persisted through days 7-14 (see black arrowhead in E and F). While there was an overall loss of immunoreactive dynamin II in the seminiferous epithelium, its level in the basal compartment of the seminiferous epithelium at the BTB persisted or even appeared to be higher on day 14 vs normal rats (see F vs C-E). This experiment was repeated twice using different sections from different experimental groups with similar results. Bar in $\mathrm{C}=80 \mu \mathrm{m}$, which applies to D-F. H, hour; D, day; Ctrl, control.

contributed by Sertoli cells, whereas the lysates from testes on day 4 and earlier time points including normal rats (Ctrl) had more proteins contributed by germ cells. As such, the data shown in Fig. 4B were corrected against the declining testicular weight (see Fig. 4C), and re-plotted as the relative target protein level per pair testes (see Fig. 4D). Consistent with the data shown in Fig. 4B on day 1, most of the target proteins (except $\beta$-catenin) were induced at the beginning of germ cell depletion (see Fig. 3). However, on days 7 and 14, when most germ cells, in particular elongating/elongate and round spermatids and most spermatocytes, were depleted from the epithelium, only $\mathrm{N}$-cadherin was still induced. This observation is consistent with an earlier report (Chen et al.
2003). Yet the levels of $\beta$-catenin, occludin, and ZO-1, did not appear to be significantly different from the controls (Fig. 4D vs B). In fact, a mild inhibition was detected for $\beta$-catenin on day 14 (Fig. 4D vs B).

\section{Changes in protein-protein interactions at the BTB during junction restructuring in the seminiferous epithelium}

We next used samples from testes of adjudin-treated rats to examine changes in the association of the BTB target proteins with dynamin II by Co-IP as shown in Fig. 5. When these testes lysates were examined for dynamin II protein level, a significant decline in overall dynamin II level was detected 
A

Time after treatment of rats with adjudin (50 mg/kg b.w., by gavage)

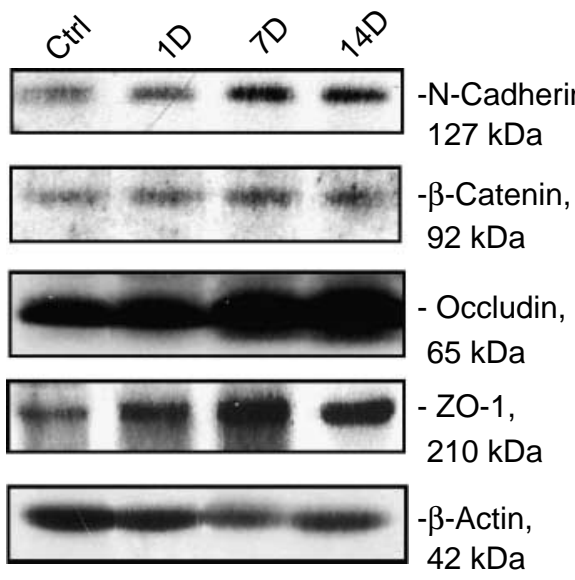

C

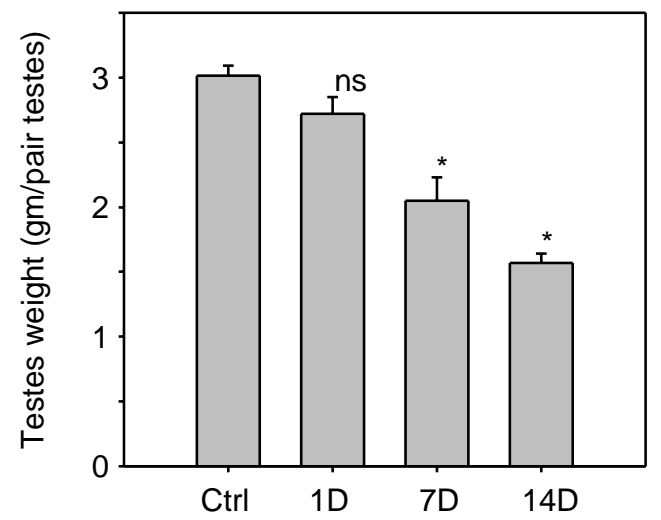

Time after treatment of rats with adjudin (50 mg/kg b.w., by gavage)
B

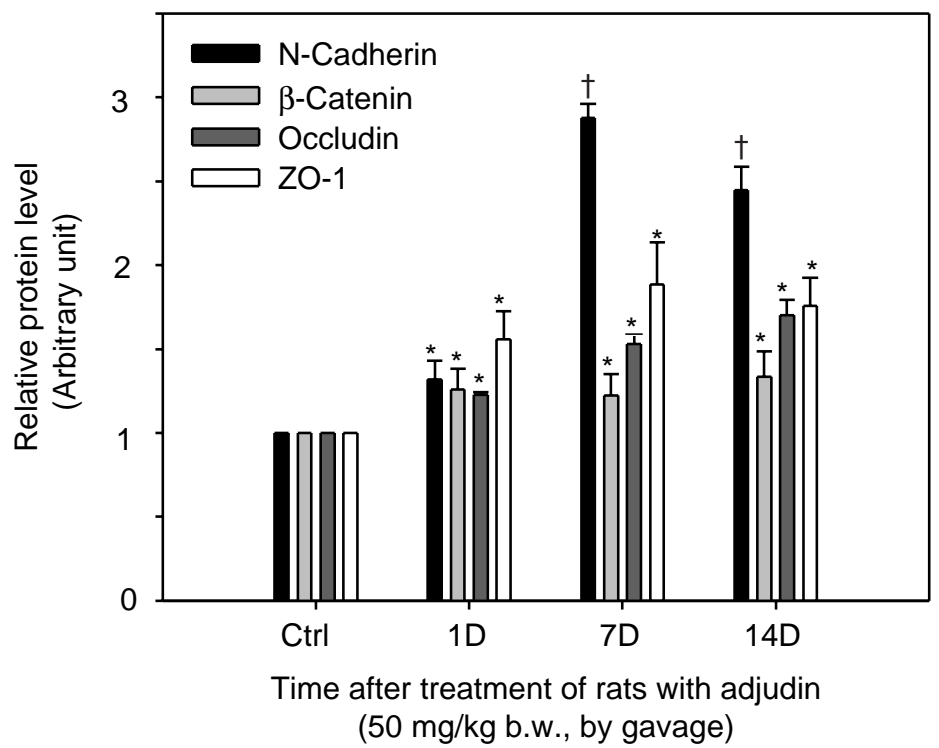

D

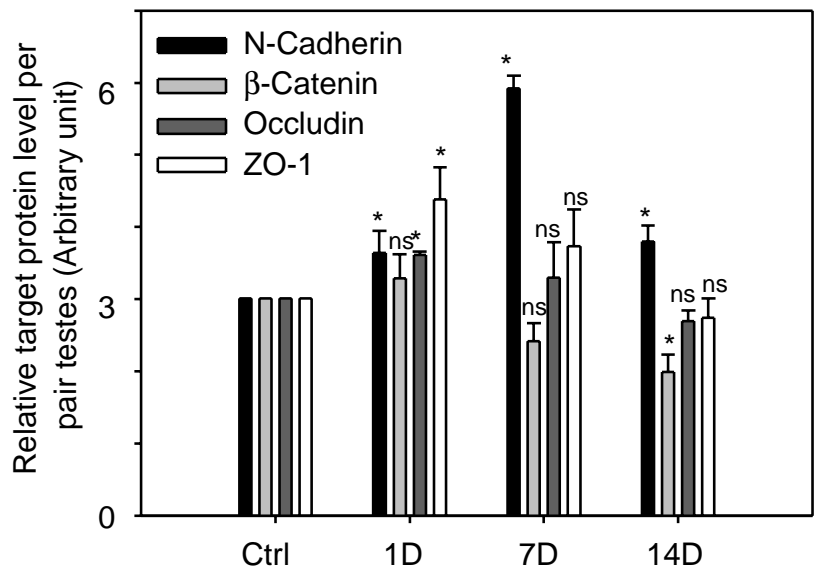

Time after treatment of rats with adjudin (50 mg/kg b.w., by gavage)

Figure 4 (A-D) Changes in the steady-state protein levels of BTB-associated protein complexes during adjudin-induced germ cell depletion from the seminiferous epithelium. (A) About $100 \mu \mathrm{g}$ protein from testes lysates on 1, 7, and 14 days after adjudin treatment and the control (Ctrl, normal testes at time 0) were resolved by SDS-PAGE. Immunoblotting was carried out using antibodies against different proteins in the $\mathrm{N}$-cadherin/ $\beta$-catenin and the occludin/ZO-1 protein complexes. $\beta$-Actin served as the protein loading control. This is a representative result from 4 separate experiments, which yielded similar results and are shown in B. (B) This is a histogram using data shown in $A$ and normalized against $\beta$-actin $(n=4)$. The steady-state protein level in Ctrl was arbitrarily set as 1 , against which other data were compared. *Significantly different, $P<0 \cdot 05$ by ANOVA; ${ }^{+} P<0 \cdot 01$. (C) Changes in testes weight (per pair testes) after adjudin treatment. (D) Data shown in (C) were corrected against the declining testes weight and expressed as relative protein level per pair testes. Statistical analysis shown in $C$ and D was performed using ANOVA; ns, not significantly different; $\mathrm{D}$, days; Ctrl, control. ${ }^{*} P<0 \cdot 05$.

(see the sixth panel in Fig. 5A, the seventh panel is $\beta$-actin that serves as a protein loading control; and the lower panel in Fig. 5B). This was consistent with results shown in Fig. 3. The drop in total protein level of dynamin II in the testis on day 7 was accompanied by a loss of association between dynamin II and occludin as well as $\mathrm{N}$-cadherin, which might be explained by the reduced dynamin II protein level at that time point (see also Fig. 2). Interestingly, at the same time, there was a significant increase in the association of dynamin II with ZO-1 and $\beta$-catenin, the corresponding adaptors of occludin and 
A

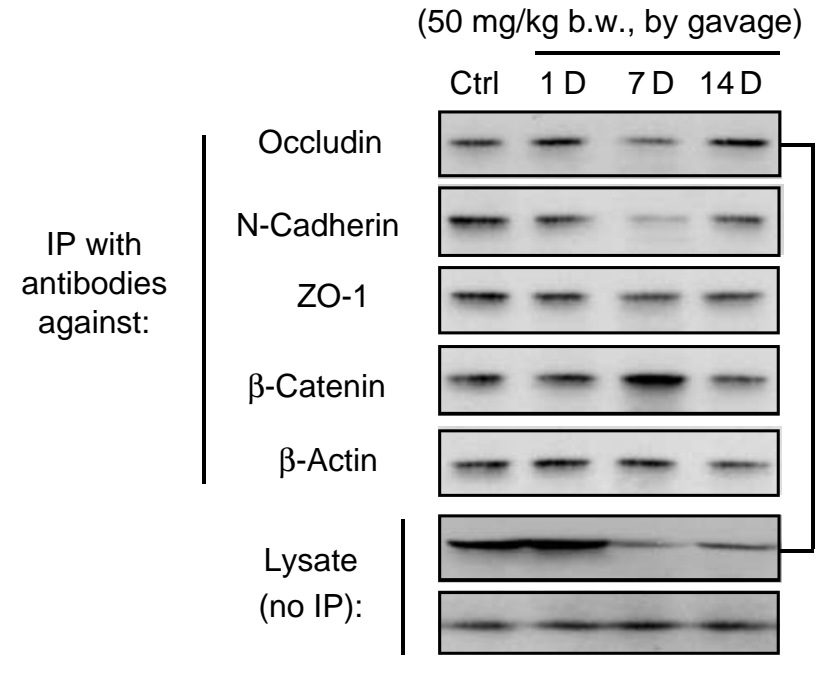

B

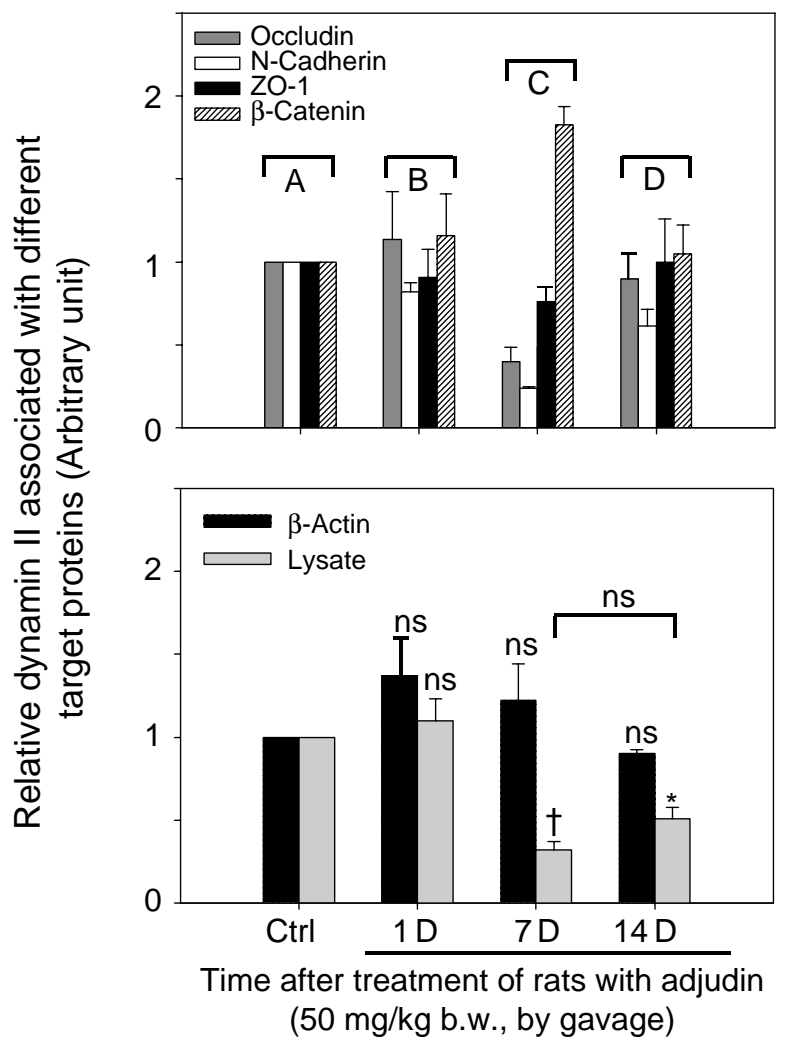

IB: Dynamin II

IB: $\beta$-Actin
A vs. $B=$ n.s.

A vs. $\mathrm{C}$ or $\mathrm{B}$ vs. $\mathrm{C}=P<0.01$

A vs. $D$ or $B$ vs. $D=$ n.s.

C vs. $\mathrm{D}=P<0.01$

Figure 5 ( $\mathrm{A}$ and B) A study by Co-IP to assess changes in protein-protein interactions between dynamin II, integral membrane proteins, and adaptors at the BTB. (A) Specific antibodies against different target proteins were used to immunoprecipitate dynamin II. It was observed that a loss in association between dynamin II and integral membrane proteins at the BTB: occludin and N-cadherin, occurred on day 7 (7D) after adjudin treatment (see also Fig. 3C-F), which was the time of germ cell depletion from the epithelium. This was concomitant with a loss of dynamin II from the BTB (see the lower panel). However, a significant increase in the association between dynamin II and the two adaptors: ZO-1 and $\beta$-catenin was detected. Also, by day 14 posttreatment, while the dynamin II level was still low, an increase in protein-protein association of dynamin II with occludin and $\mathrm{N}$-cadherin was detected (see the fifth panel in which testis lysates were stained for dynamin II by 
$\mathrm{N}$-cadherin (Fig. 5A and B). Although the levels of dynamin II in the testis on days 7 and 14 remained low (vs Ctrl and day 1) and were not statistically significantly different from each other (see Fig. 5B), the binding between dynamin II and the two BTB protein complexes rebound by day 14 (Fig. 5A and B). These observations are physiologically important, as they suggest that when the tubules were almost devoid of germ cells on days 7 and 14 following adjudin treatment (see Fig. 3E and F vs $\mathrm{C}$ and $\mathrm{D}$ ), the association between dynamin II and the two BTB junctional complexes, namely occludin/ZO-1 and $\mathrm{N}$-cadherin/ $\beta$-catenin, become tighter. These biochemical results are also supported by immunohistochemistry studies, showing that by day 14 when the tubules were virtually devoid of spermatids and spermatocytes (see Fig. 3F), dynamin II staining in the basal compartment of the seminiferous tubule and at the BTB did not diminish vs control rats (see Fig. 3F vs C). In short, the changes in protein-protein association between dynamin II and the adaptors ZO-1 and $\beta$-catenin on days 7 and 14 vs controls and day 1 (see Fig. 5) could not be explained simply by an alteration of steady-state protein levels. Instead, there was a shift in affinity between dynamin II and the adaptors.

\section{Discussion}

\section{What is the physiological role of dynamin II at the BTB?}

Dynamin II is most abundantly found in the testis vs other organs (Iguchi et al. 2002). However, its physiological role in the testis remains unknown. Studies in other epithelia have demonstrated that dynamins are crucial for endocytosis of integral membrane proteins at cell junctions, such as occludin, and they are involved in protein-trafficking events between cell membrane and the actin network (Oh et al. 1998, Schmid et al. 1998, Sever et al. 2000a, Orth \& McNiven 2003, Shen \& Turner 2005). Moreover, recent studies have shown that membrane protein internalization and its recycling are important for regulating junction dynamics in multiple epithelia (for a review, see Maxfield \& McGraw (2004)). In general, this process of protein internalization is regulated by clathrin- or caveolin-mediated pathways (Le et al. 1999, Ivanov et al. 2004, Shen \& Turner 2005), or alternatively by a clathrin- and caveolin-independent mechanism such as pinocytosis (Utech et al. 2005). Dynamins are known to be involved in both clathrin- and caveolinmediated protein trafficking (Oh et al. 1998, Shen \& Turner 2005), facilitating internalization, and recycling of integral membrane proteins. However, it remains to be investigated if dynamin II indeed is involved in promoting internalization and recycling of occludins, cadherins, JAM-A, and claudins at the BTB; but since dynamin II was found to co-localize with clathrin in Sertoli cells (Kamitani et al. 2002), its role in cellular protein trafficking was implicated. Furthermore, recent studies have provided strong support for the model in which dynamins function as pinchase-like mechanoenzymes, to sever nascent endocytic pits from the plasma membrane to form endocytic vesicles, rather than acting as molecular switches like small GTPases (Thompson \& McNiven 2001, Cao et al. 2003). Thus, it is highly likely that dynamin II acts as a 'pinchase-like mechanoenzyme' in Sertoli cells, similar to other epithelial cells, to facilitate internalization of occludin and/or $\mathrm{N}$-cadherin.

It is obvious that the best approach to assess the function of dynamins at the BTB is to examine the testes of dynamin knockout mice. Yet, dynamin knockout mice are presently unavailable, thus it is not known if the deletion of any one of the three classical dynamins would affect spermatogenesis and/or BTB function. Nonetheless, in light of the extensive junction restructuring events at the BTB during spermatogenesis at stage VIII of the epithelial cycle to facilitate preleptotene spermatocyte migration across the barrier (Russell 1977), we sought to examine the possible involvement of dynamin II in the protein complexes at the BTB using a different approach. Studies were carried out by a model of junction restructuring in which adult rats were treated with adjudin (Mruk \& Cheng 2004). In normal testes, it was shown that dynamin II was associated with the two most extensively studied protein complexes at the BTB, namely occludin/ZO-1 and $\mathrm{N}$-cadherin/ $\beta$-catenin. It is also worthy of note that the association between dynamin II and the adaptors in these two complexes, namely $\mathrm{ZO}-1$ and $\beta$-catenin, significantly increased during germ cell depletion. In other epithelia, TJ fibrils are restricted to the apical region

immunoblotting, see also Fig. 3A and B). The data shown herein are the results of a single experiment, representing three experiments using different samples, which yielded similar results and are shown in (B). (B) These two histograms summarize the results of the Co-IP with $n=3$. For statistical comparison, the target proteins were grouped into four panels as shown in the upper panel as A, B, C and D. On the right side of upper panel, target proteins in A were compared with the corresponding target proteins in B; or A-C, and the like (see legend on the right side of upper panel). In the comparisons of $\mathrm{A}: \mathrm{C}$ and $\mathrm{B}: \mathrm{C}$, the column for ZO-1 did not change statistically, but since there was a significant decline in the steady-state dynamin II level (see lower panel in B), a declining association between ZO-1 and dynamin II was expected. Instead, a significant increase in the association of ZO-1 and dynamin II was detected on day 7 after adjudin treatment. As for the comparison of dynamin II protein level in lysates (see shaded bar in lower panel in B), while there was a significant decline in dynamin II level on days 7 and 14 vs control (Ctrl) or day 1, the dynamin II levels remained low at these two time points and they were not significantly different from each other. Collectively, these data illustrate that while there was a loss in protein-protein association of dynamin II with occludin and $\mathrm{N}$-cadherin, dynamin II was more tightly associated with the two adaptors (i.e. ZO- 1 and $\beta$-catenin) by day 7 and by day 14 , a rise in proteinprotein association was found between all of these four target proteins and dynamin II. ns, not significantly different by ANOVA; ${ }^{*} P<0 \cdot 05 ;{ }^{\dagger} P<0 \cdot 01$. 
of epithelial cells, beneath these are the AJ plaques and followed by the desmosomes, forming the junction complexes (Alberts et al. 2002). In light of such intimate association between $\mathrm{TJ}$ and $\mathrm{AJ}$, a disruption of $\mathrm{AJ}$ is known to perturb the TJ barrier in virtually all the epithelia and endothelia examined to date (Man et al. 2000, West et al. 2002, Guo et al. 2003). However, this general cell physiological response is not applicable to the seminiferous epithelium. Otherwise, the BTB cannot maintain its 'fence' and 'immunological barrier' functions during spermatogenesis when developing preleptotene spermatocytes are traversing the BTB at stage VIII of the epithelial cycle. Additionally, TJ and AJ are even more intimately associated at the BTB vs other epithelia and endothelia. This is because at the BTB, TJs 'co-exist' sideby-side with desmosome-like junctions and two types of testisspecific AJ, namely basal ES and basal tubulobulbar complex (basal TBC). Hence, it is conceivable that although the disruption of $\mathrm{AJ}$ usually leads to $\mathrm{TJ}$ disassembly, a unique mechanism is in place in the testis to 'disengage' the events of $\mathrm{TJ}$ and $\mathrm{AJ}$ disassembly pertinent to spermatogenesis. Indeed, recent studies have shown that the testis apparently utilizes a 'disengagement' and 'engagement' mechanism to ensure the integrity of TJs during AJ restructuring (Yan \& Cheng 2005). For instance, it was shown that the co-existing occludin/ZO-1 and $\mathrm{N}$-cadherin/ $\beta$-catenin complexes were structurally 'engaged' in normal testes via their adaptors, ZO-1 and $\beta$-catenin, to reinforce BTB integrity, creating the tightest barrier in the mammalian body (Yan \& Cheng 2005).

However, when the testis undergoes restructuring during spermatogenesis or when $\mathrm{AJ}$ restructuring is induced by adjudin treatment, $\mathrm{ZO}-1$ is dissociated from $\beta$-catenin, i.e. in a 'disengagement' state. As such, the occludin/ZO-1 and $\mathrm{N}$-cadherin/ $\beta$-catenin protein complexes are not structurally 'engaged' but rather 'disengaged'. This permits AJ restructuring to facilitate germ cell movement without compromising the occludin-ZO-1 interactions at the BTB. As reported herein, dynamin II became more significantly 'engaged' with ZO-1 and $\beta$-catenin during extensive $\mathrm{AJ}$ restructuring induced by adjudin, which may explain the lack of damage to the BTB at the time of germ cell loss during adjudin-induced AJ restructuring (Mruk \& Cheng 2004). This phenomenon seemingly suggests that dynamin II may play a role in assisting the 'disengagement' of ZO-1 and $\beta$-catenin by pulling them away from each other during adjudin-induced junction restructuring so that these adaptors can associate primarily with their corresponding integral membrane proteins, occludin and $\mathrm{N}$-cadherin respectively. In this way, the occludin-ZO-1 complex can continue to maintain the TJ barrier. This postulation is also supported by the protein-protein interaction data. By day 14 when virtually all the tubules were devoid of germ cells with only Sertoli cells and spermatogonia found in the basal compartment, there was an increase in the association between dynamin II and the two major junctional protein complexes at the BTB.

Obviously, future investigations should be expanded to examine the changes in the kinetics of internalization and recycling of BTB integral membrane proteins (e.g. occludin,
$\mathrm{N}$-cadherin, and/or JAM-A) following adjudin treatment, using seminiferous tubule cultures and the techniques of biotinylation, immunoblotting, and co-immunoprecipitation. In addition, the functional significance of the changes in association between dynamin II and ZO- $1 / \beta$-catenin, as presented in this report, should be carefully evaluated.

In this context, it is of interest to note that while dynamin II is found in the BTB and may be crucial to BTB dynamics, it is the most abundantly detected at the apical ES in a stage specific manner (i.e. at early stage VIII). This seemingly suggests that dynamin II may also facilitate protein internalization at the apical ES during spermiation, which should be investigated in future studies.

\section{Is the adjudin-induced AJ restructuring and germ cell loss a reliable model to probe the function of dynamin II?}

It is obvious that the results reported herein were based on the use of the adjudin model and comparison with testes from normal rats. As such, one would argue if the observed changes in protein-protein interactions reported herein were simply the result of drug toxicity, and they might be irrelevant to normal testicular physiology. We offer several explanations to support our conclusion. First, recently completed acute toxicity studies in mice and rats, as well as pertinent mutagenicity and genotoxicity conducted by licensed toxicologists according to FDA guidelines, have shown that adjudin is not toxic at doses effective to induce transient infertility in these animals (Mruk et al. 2006). However, as illustrated in a 29-day subchronic toxicity study, a narrow margin between adjudin's safety and efficacy was detected, making it unlikely to become a male contraceptive unless it can be targeted specifically to the testis to improve its efficacy and selectivity (Mruk et al. 2006). These toxicity studies thus illustrate that the data reported herein were not likely to be the manifestation of drug toxicity. Secondly, if adjudin is indeed acutely toxic to Sertoli and/or germ cells, its infertility effects would have been more rapid when it was administered to adult rats at $50 \mathrm{mg} / \mathrm{kg}$ b.w. (once a week for $2-4$ weeks) by gavage, without requiring a $\sim 20$-day wait period for the sperm reserve in the epididymides to be exhausted (Cheng et al. 2001, 2005). Furthermore, the anti-fertility effect of adjudin was highly reversible when rats were given just two to six doses at $50 \mathrm{mg} / \mathrm{kg}$ b.w. (once a week for 2-6 weeks), suggesting that at these dosings, not all Sertoli cells and spermatogonia were killed by the adjudin treatment (Cheng et al. 2005). Nonetheless, these findings do not rule out the possibility that adjudin is a Sertoli and/or germ cell toxicant, in particular if it is given chronically. Thirdly, recent studies from our laboratory using the adjudin model have identified the signaling molecules and pathways, such as focal adhesion kinase (FAK), Src, and extracellular signal-regulated kinase (ERK) which is one of the mitogen-activated protein kinases, crucial for regulating cell adhesion in the epithelium particularly between Sertoli cells and elongating/elongate spermatids at the apical ES (Siu et al. 2005, Xia \& Cheng 2005). These findings have largely been confirmed using a well-established and thoroughly 
characterized in vivo model for studying AJ dynamics in the testis by testosterone/estradiol implants to suppress the intratesticular androgen level (O'Donnell et al. 1996, 2000, Saito et al. 2000, Beardsley \& O'Donnell 2003); (for reviews, see O'Donnell et al. 2001, McLachlan et al. 2002). In this model, the suppression of endogenous androgen level resulted in a selective disruption of apical ES at the Sertoli cell-spermatid (step 8 and beyond) interface without apparent toxic effects to testicular cells since germ cells eventually repopulated the epithelium during recovery, and the BTB integrity was also not compromised (O'Donnell et al. 2000, Beardsley \& O'Donnell 2003). For instance, a study using this androgen suppression model has shown that $\mathrm{CSrc}$, FAK, and ERK are indeed the crucial kinases in the ERK-signaling pathway that regulates apical ES dynamics (Wong et al. 2005), which is consistent with the results obtained from the adjudin model (Siu et al. 2005, Xia \& Cheng 2005). Lastly and perhaps the most important of all, as shown in studies using the androgen suppression model, the observed changes in cadherins-catenins interactions in the epithelium as a result of increasing tyrosine phosphorylation in $\beta$-catenin, ultimately led to germ cell loss from the epithelium (Xia et al. 2005b, Zhang et al. 2005); and these results were consistent with data obtained from the adjudin model (Xia \& Cheng 2005, Yan \& Cheng 2005). Collectively, the above
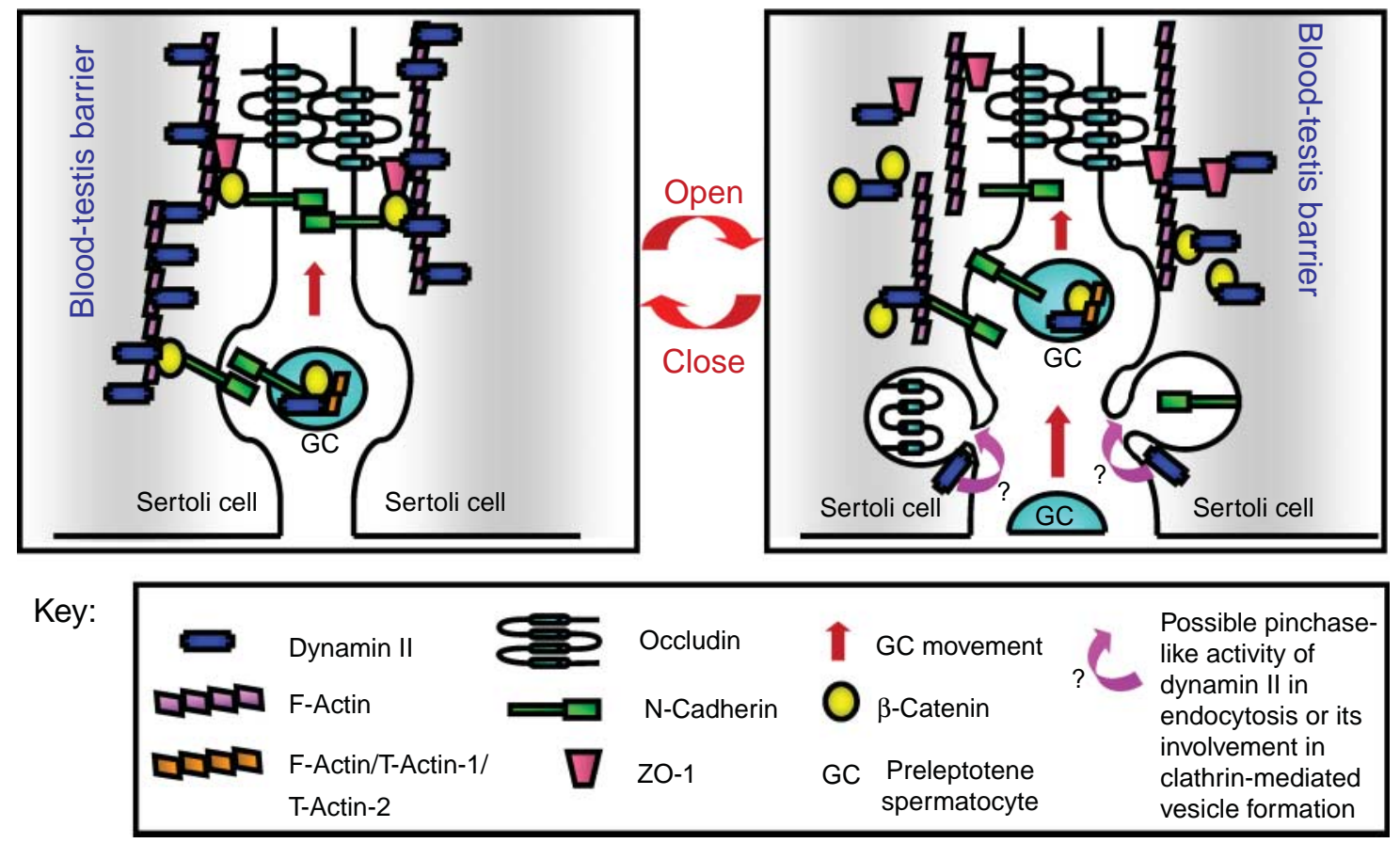

Figure 6 A schematic drawing illustrating the dynamic interaction between dynamin II and the adaptors ZO- 1 and $\beta$-catenin that may play a role in regulating tight junction dynamics and cell adhesion at the BTB. The changes in interaction between dynamin II and the adaptor proteins at the occludin/ZO-1 and the $\mathrm{N}$-cadherin/ $\beta$-catenin complexes during BTB restructuring may have physiological significance in spermatogenesis of adult rat testes. The panel on the left depicts the BTB in a 'closed' state, where ZO- 1 and $\beta$-catenin interact with each other so that the co-existing occludin/ZO-1 and N-cadherin/ $\beta$-catenin protein complexes reinforce the BTB integrity (Yan \& Cheng 2005). When the BTB is in the 'open state' as shown in the right panel (either during junction restructuring in spermatogenesis or induced by adjudin treatment), dynamin II becomes associated more extensively with ZO- 1 and $\beta$-catenin. This may play a role in causing the 'disengagement' of the integral membrane proteins, and their interactions with adaptors in the occludin/ZO- 1 and $\mathrm{N}$-cadherin/ $\beta$-catenin protein complexes, facilitating BTB opening and preleptotene spermatid migration during stage VIII of the epithelial cycle. In addition, the change in association between dynamin II and the adaptor proteins may be used to maintain the 'disengaged' state of the BTB. On the other hand, the right panel of this diagram also includes another postulated function of dynamin II in the seminiferous epithelium, based on findings in other epithelia, which is the internalization of integral membrane proteins (e.g. occludin and N-cadherin) by endocytic processes. Dynamin II may act as a 'pinchase' to facilitate endocytic vesicle formation by severing nascent endocytic pits from the plasma membrane as proposed earlier (Thompson \& McNiven 2001, Cao et al. 2003). It is worthy to note that dynamins per se are not proteases, it is likely that adaptors that are associated with dynamins recruit protease(s) to the site to facilitate its 'pinchase-like' action. As such, dynamin II may have multiple functions in the seminiferous epithelium, which must be vigorously investigated in future studies. Nevertheless, the proposed 'pinchase' function of dynamin II does not negate our findings. The 'opening' state of the BTB is likely to be induced by a surge of cytokines released from Sertoli and germ cells (e.g. TGF- $\beta 3$ and TNF $\alpha$ ), with receptors largely restricted to Sertoli cells (Lui et al. 2003b, Siu et al. 2003, Li et al. 2006, Xia et al. 2006). This is a highly simplified hypothetical scheme, since the BTB is composed of at least five different classes of protein complexes, namely occludin/ZO-1, claudins/ZO-1, JAMs/ZO-1, cadherins/catenins, and nectins/afadins. Different classes of protein complexes are probably regulated differently. This model is expected to be revised rapidly. However, it serves as a biochemical scheme upon which functional experiments can be designed to investigate the functional significance of the change in the dynamin II-adaptor proteins association as presented in this report, and also the possible role of dynamin II in integral membrane protein internalization. 
arguments illustrate that even if adjudin is a Sertoli cell toxicant, it produces changes in the seminiferous epithelium including the BTB and induces junction restructuring at the cell-cell interface, which can be used to learn something about the normal system. Thus, the results presented in this report are physiologically relevant to events that occur in the seminiferous epithelium during spermatogenesis.

What is the physiological significance regarding changes in protein-protein interactions at the $B T B$ pertinent to preleptotene spermatocyte migration across the BTB at stage VIII of the epithelial cycle?

Recent studies have shown that at least five different structural protein complexes (excluding their isoforms) are found at the $\mathrm{BTB}$, conferring barrier and anchoring functions in adult rat testes. These include claudins/ZO-1, JAMs/ZO-1, and nectins/afadins, in addition to the previously mentioned occludin/ZO-1 and N-cadherin/ $\beta$-catenin (Wong \& Cheng 2005, Xia et al. 2005a). Undoubtedly, we will see this list grow in the years to come. At the BTB, these co-existing protein complexes and the different junction types serve to maintain not only the BTB integrity but also the cell polarity. More importantly, they ensure the timely BTB restructuring that facilitates preleptotene spermatocyte movement during stage VIII of the epithelial cycle in adult rat testes. It would be physiologically 'difficult', perhaps even 'uneconomical', to have de novo synthesis of all these proteins simultaneously at the $\mathrm{BTB}$ each time the preleptotene spermatocytes traverse the BTB. For this reason, protein complexes at the BTB may employ an efficient mechanism to allow rapid BTB restructuring. As illustrated by recent studies using different models, the changes in protein-protein interactions at the BTB or apical ES are indeed being used to facilitate $\mathrm{AJ}$ and/or $\mathrm{TJ}$ restructuring in the seminiferous epithelium, so as to elicit rapid changes in cell adhesion (Xia et al. 2005b, Yan \& Cheng 2005). Studies from other epithelia have shown that cadherins can be shuffled rapidly to the cytoplasm via internalization, and re-shuffled back to the plasma membrane with the help of GTPases, kinases, and adaptors (e.g. Rap1, PKC, p120 ${ }^{\text {ctn }}$; Le et al. 1999, 2002, Balzac et al. 2005, Mruk et al. 2005, Xiao et al. 2005). In addition, GTPases (e.g. dynamin II) are likely to be involved in these protein-trafficking events, and some of them may act as molecular switches for trafficking between cell membrane and cytoskeletal networks in various epithelia, including the seminiferous epithelium in adult rat testes (Olkkonen \& Stenmark 1997, Takai et al. 2001, Deneka et al. 2003, Mruk et al. 2005). Work is now in progress in our laboratory to assess internalization and recycling of integral membrane proteins at the Sertoli-Sertoli and the Sertoli-germ cell interfaces, and the factor(s) and/or mechanism(s) that regulate these events.

In summary, we have demonstrated that dynamin II is a potentially important regulator for the protein-protein interactions between different adaptors (e.g. catenins and ZO-1) and their corresponding integral membrane proteins (e.g. cadherins and occludins) in rat testes. Based on these recent data including the results reported herein, we have provided a hypothetical model (see Fig. 6) illustrating the dynamic interactions between GTPases (e.g. dynamin II) and the corresponding BTB-associated protein complexes (e.g. occludin/ZO-1 and $\mathrm{N}$-cadherin/ $\beta$-catenin), to facilitate preleptotene spermatocyte migration across the $\mathrm{BTB}$ without compromising its integrity.

\section{Acknowledgements}

This work was supported in part by grants from the National Institutes of Health (NICHD, U01 HD045908 to C Y C, U54 HD029990 Project 3 to C Y C), the CONRAD Program (CICCR CIG 01-72 to C Y C; CIG 01-74 to D D M), and Hong Kong Research Grant Council (HKU 7413/04M and HKU 7536/05M to W M L). P P Y L studied as a summer intern in the C Y C Laboratory in New York, and was supported in part by a fellowship from the University of Hong Kong. Subsequent experiments were completed by W X, C Q F W and D D M in C Y C Laboratory. The authors declare that there is no conflict of interest that would prejudice the impartiality of this scientific work.

\section{References}

Alberts B, Johnson A, Lewis J, Raff M, Roberts K \& Walter P 2002 Molecular Biology of the Cell. New York: Garland Science.

Aravindan GR, Pineau C, Bardin CW \& Cheng CY 1996 Ability of trypsin in mimicking germ cell factors that affect Sertoli cell secretory function. Journal of Cellular Physiology 168 123-133.

Balzac F, Avolio M, Degani S, Kaverina I, Torti M, Silengo L, Small JV \& Retta SF 2005 E-Cadherin endocytosis regulates the activity of Rap1: a traffic light GTPase at the crossroads between cadherin and integrin function. Journal of Cell Science 118 4765-4783.

Beardsley A \& O'Donnell L 2003 Characterization of normal spermiation and spermiation failure induced by hormone suppression in adult rats. Biology of Reproduction 68 1299-1307.

Bradford MM 1976 A rapid and sensitive method for the quantitation of microgram quantities of protein utilizing the principle of protein-dye binding. Analytical Biochemistry 72 248-254.

Cao H, Orth JD, Chen J, Weller SG, Heuser JE \& McNiven MA 2003 Cortactin is a component of clathrin-coated pits and participates in receptor-mediated endocytosis. Molecular and Cellular Biology 23 2162-2170.

Chapin RE, Wine RN, Harris MW, Borchers CH \& Haseman JK 2001 Structure and control of a cell-cell adhesion complex associated with spermiation in rat seminiferous epithelium. Journal of Andrology 22 1030-1052.

Chen YM, Lee NPY, Mruk DD, Lee WM \& Cheng CY 2003 Fer kinase/Fer $\mathrm{T}$ and adherens junction dynamics in the testis: an in vitro and in vivo study. Biology of Reproduction 69 656-672.

Cheng CY \& Mruk DD 2002 Cell junction dynamics in the testis: Sertoligerm cell interactions and male contraceptive development. Physiological Reviews 82 825-874.

Cheng CY, Silvestrini B, Grima J, Mo MY, Zhu LJ, Johansson E, Saso L, Leone MG, Palmery M \& Mruk D 2001 Two new male contraceptives exert their effects by depleting germ cells prematurely from the testis. Biology of Reproduction 65 449-461.

Cheng CY, Mruk DD, Silvestrini B, Bonanomi M, Wong CH, Siu MKY, Lee NPY, Lui WY \& Mo MY 2005 AF-2364 [1-(2,4-dichlorobenzyl)-1Hindazole-3-carbohydrazide] is a potential male contraceptive: a review of recent data. Contraception 72 251-261. 
Crans DC, Bunch RL \& Theisen LA 1989 Interaction of trace levels of vanadium (IV) and vanadium (V) in biological systems. Journal of the American Chemical Society 111 7597-7607.

Deneka M, Neeft M \& van der Sluijs P 2003 Regulation of membrane transport by Rab GTPases. Critical Reviews in Biochemistry and Molecular Biology 38 121-142.

Galdieri M, Ziparo E, Palombi F, Russo MA \& Stefanini M 1981 Pure Sertoli cell cultures: a new model for the study of somatic-germ cell interactions. Journal of Andrology $\mathbf{5}$ 249-259.

Guo X, RaoJN, Liu L, Zou TT, Turner DJ, Bass BL \& WangJY 2003 Regulation of adherens junctions and epithelial paracellular permeability: a novel function for polyamines. American Journal of Physiology 285 C1174-C1187.

Hinshaw JE 2006 Filling the GAP for dynamin. Nature Cell Biology 8 432-433.

Huyer G, Liu S, Kelly J, Moffat J, Payette P, Kennedy B, Tsaprailis G, Gresser MJ \& Ramachandran C 1997 Mechanism of inhibition of protein-tyrosine phosphatases by vanadate and pervanadate. Journal of Biological Chemistry 272 843-851.

Iguchi H, Watanabe M, Kamitani A, Nagai A, Hosoya O, Tsutsui K \& Kumon H 2002 Localization of dynamin 2 in rat seminiferous tubules during the spermatogenic cycle. Acta Medica Okayama 56 205-209.

Ivanov AI, Nusrat A \& Parkos CA 2004 Encytosis of epithelial apical junctional proteins by a clathrin-mediated pathway into a unique storage compartment. Molecular Biology of the Cell 15 176-188.

Johnson KJ \& Boekelheide K 2002 Dynamic testicular adhesion junctions are immunologically unique. II. Localization of classic cadherins in rat testis. Biology of Reproduction 66 992-1000.

Kamitani A, Yamada H, Kinuta M, Watanabe M, Li SA, Matsukawa T, McNiven M, Kumon H \& Takei K 2002 Distribution of dynamins in testis and their possible relation to spermatogenesis. Biochemical and Biophysical Research Communications 294 261-267.

Kruchten AE \& McNiven MA 2006 Dynamin as a mover and pincher during cell migration and invasion. Journal of Cell Science 119 1683-1690.

Le TL, Yap AS \& Stow JL 1999 Recycling of E-cadherin: a potential mechanism for regulating cadherin dynamics. Journal of Cell Biology 146 219-232.

Le TL, Joseph SR, Yap AS \& Stow JL 2002 Protein kinase C regulates endocytosis and recycling of E-cadherin. American Journal of Physiology. Cell Physiology 283 C489-C499.

Lee NPY, Mruk D, Lee WM \& Cheng CY 2003 Is the cadherin/catenin complex a functional unit of cell-cell-actin-based adherens junctions (AJ) in the rat testis? Biology of Reproduction 68 489-508.

Li MWM, Xia W, Mruk DD, Wang CQF, Yan HHN, Siu MKY, Lui WY, Lee WM \& Cheng CY 2006 Tumor necrosis factor $\alpha$ reversibly disrupts the blood-testis barrier and impairs Sertoli-germ cell adhesion in the seminiferous epithelium of adult rat testes. Journal of Endocrinology $190313-329$.

Lui WY, Lee WM \& Cheng CY 2003a Rho GTPases and spermatogenesis. Biochimica et Biophysica Acta 1593 121-129.

Lui WY, Lee WM \& Cheng CY $2003 b$ Transforming growth factor- $\beta 3$ regulates the dynamics of Sertoli cell tight junctions via the p38 mitogenactivated protein kinase pathway. Biology of Reproduction 68 1597-1612.

Man Y, Hart VJ, Ring CJ, Sanjar S \& West MR 2000 Loss of epithelial integrity resulting from $\mathrm{E}$-cadherin dysfunction predisposes airway epithelial cells to adenoviral infection. American Journal of Respiratory Cell and Molecular Biology 23 610-617.

Maxfield FR \& McGraw TE 2004 Endocytic recycling. Nature Reviews. Molecular Cell Biology 5 121-132.

McLachlan RI, O'Donnell L, Meachem SJ, Stanton PG, de Kretser DM, Pratis K \& Robertson DM 2002 Hormonal regulation of spermatogenesis in primates and man: insights for development of the male hormonal contraceptive. Journal of Andrology 23 149-162.

McNiven MA, Cao H, Pitts KR \& Yoon Y 2000 The dynamin family of mechanoenzymes: pinching in new places. Trends in Biochemical Sciences $\mathbf{2 5}$ $115-120$.

Mruk DD \& Cheng CY 2004 Sertoli-Sertoli and Sertoli-germ cell interactions and their significance in germ cell movement in the seminiferous epithelium during spermatogenesis. Endocrine Reviews 25 747-806.
Mruk D, Zhu LJ, Silvestrini B, Lee WM \& Cheng CY 1997 Interactions of proteases and protease inhibitors in Sertoli-germ cell cocultures preceding the formation of specialized Sertoli-germ cell junctions in vitro. Journal of Andrology 18 612-622.

Mruk DD, Siu MKY, Conway AM, Lee NPY, Lau ASN \& Cheng CY 2003 Role of tissue inhibitor of metalloproteases- 1 in junction dynamics in the testis. Journal of Andrology 24 510-523.

Mruk DD, Lau ASN \& Conway AM 2005 Crosstalk between Rab GTPases and cell junctions. Contraception 72 280-290.

Mruk DD, Wong CH, Silvestrini B \& Cheng CY 2006 A male contraceptive targeting germ cell adhesion. Nature Medicine In Press.

O'Donnell L, McLachlan RI, Wreford NG, de Kretser DM \& Robertson DM 1996 Testosterone withdrawl promotes stage-specific detachment of round spermatids from the rat seminiferous epithelium. Biology of Reproduction $\mathbf{5 5}$ 895-901.

O’Donnell L, Stanton PG, Bartles JR \& Robertson DM 2000 Sertoli cell ectoplasmic specializations in the seminiferous epithelium of the testosterone-suppressed adult rat. Biology of Reproduction 63 99-108.

O'Donnell L, Robertson KM, Jones ME \& Simpson ER 2001 Estrogen and spermatogenesis. Endocrine Reviews 22 289-318.

Oh P, McIntosh DP \& Schnitzer JE 1998 Dynamin at the neck of caveolae mediates their budding to form transport vesicles by GTP-driven fission from the plasma membrane of endothelium. Journal of Cell Biology 141 101-114.

Olkkonen VM \& Stenmark H 1997 Role of Rab GTPases in membrane traffic. International Review of Cytology 176 1-85.

Orth JD \& McNiven MA 2003 Dynamin at the actin-membrane interface. Current Opinion in Cell Biology 15 31-39.

Robinet P, Fradagrada A, Monier MN, Marchetti M, Cogny A, Moatti N, Paul JL, Vedie B \& Lamaze C 2006 Dynamin is involved in endolysosomal cholesterol delivery to the endoplasmic reticulum: role in cholesterol homeostasis. Traffic 7 811-823.

Russell LD 1977 Movement of spermatocytes from the basal to the adluminal compartment of the rat testis. American Journal of Anatomy 148 313-328.

Saito K, O’Donnell L, McLachlan RI \& Robertson DM 2000 Spermiation failure is a major contributor to early spermatogenic suppression caused by hormonal withdrawal in adult rats. Endocrinology 141 2779-2785.

Schmid SL, McNiven M \& De Camilli P 1998 Dynamin and its partners: a progress report. Current Opinion in Cell Biology 10 504-512.

Sever S, Damke H \& Schmid SL 2000a Dynamin:GTP controls the formation of constricted coated pits, the rate limiting step in clathrin-mediated endocytosis. Journal of Cell Biology 150 1137-1147.

Sever S, Damke H \& Schmid SL $2000 b$ Garrotes, springs, ratchets, and whips: putting dynamin models to the test. Traffic $1385-392$.

Shen L \& Turner JR 2005 Actin depolymerization disrupts tight junctions via caveolae-mediated endocytosis. Molecular Biology of the Cell 16 3919-3936.

Siu MKY, Lee WM \& Cheng CY 2003 The interplay of collagen IV, tumor necrosis factor- $\alpha$, gelatinase B (matrix metalloprotease-9), and tissue inhibitor of metalloprotease-1 in the basal lamina regulates Sertoli cell-tight junction dynamics in the rat testis. Endocrinology 144 371-387.

Siu MKY, Wong CH, Lee WM \& Cheng CY 2005 Sertoli-germ cell anchoring junction dynamics in the testis are regulated by an interplay of lipid and protein kinases. Journal of Biological Chemistry $\mathbf{2 8 0}$ 25029-25047.

Sluka P, O’Donnell L, Bartles JR \& Stanton PG 2006 FSH regulates the formation of adherens junctions and ectoplasmic specializations between rat Sertoli cells in vitro and in vivo. Journal of Endocrinology 189 381-395.

Takai Y, Sasaki T \& Matozaki T 2001 Small GTP-binding proteins. Physiological Reviews 81 153-208.

Thompson HM \& McNiven MA 2001 Dynamin: switch or pinchase? Current Biology 11 R850,

Toyama Y, Maekawa M \& Yuasa S 2003 Ectoplasmic specializations in the Sertoli cells: new vistas based on genetic defects and testicular toxicology. Anatomical Science International 78 1-16.

Utech M, Ivanov AI, Samarin SN, Bruewer M, TurnerJR, Mrsny RJ, Parkos CA \& Nusrat A 2005 Mechanism of IFN- $\gamma$-induced endocytosis of tight junction proteins: myosin II-dependent vacuolarization of the apical plasma membrane. Molecular Biology of the Cell 16 5040-5052. 
Vogl A, Pfeiffer D \& Redenbach D 1991 Ectoplasmic ('junctional') specializations in mammalian Sertoli cells: influence on spermatogenic cells. Annals of the New York Academy of Sciences 637 175-202.

Vogl AW, Pfeiffer DC, Mulholland D, Kimel G \& Guttman J 2000 Unique and multifunctional adhesion junctions in the testis: ectoplasmic specializations. Archives of Histology and Cytology 63 1-15.

West MR, Ferguson DJ, Hart VJ, Sanjar S \& Man Y 2002 Maintenance of the epithelial barrier in a bronchial epithelial cell line is dependent on functional E-cadherin local to the tight junctions. Cell Communication and Adhesion 9 29-44.

Wine RN \& Chapin RE 1999 Adhesion and signaling proteins spatiotemporally associated with spermiation in the rat. Journal of Andrology 20 198-213.

Wong CH \& Cheng CY 2005 The blood-testis barrier: its biology, regulation and physiological role in spermatogenesis. Current Topics in Developmental Biology 71 263-296.

Wong CH, Xia W, Lee NPY, Mruk DD, Lee WM \& Cheng CY 2005 Regulation of ectoplasmic specialization dynamics in the seminiferous epithelium by focal adhesion-associated proteins in testosterone-suppressed rat testes. Endocrinology 146 1192-1204.

Xia W \& Cheng CY 2005 TGF- $\beta 3$ regulates anchoring junction dynamics in the seminiferous epithelium of the rat testis via the Ras/ERK signaling pathway: an in vivo study. Developmental Biology 280 321-343.

Xia W, Mruk DD, Lee WM \& Cheng CY 2005a Cytokines and junction restructuring during spermatogenesis - a lesson to learn from the testis. Cytokine and Growth Factor Reviews 16 469-493.

Xia W, Wong CH, Lee NPY, Lee WM \& Cheng CY 2005b A disruption of Sertoli-germ cell adhesion function in the seminiferous epithelium of the rat testis can be limited to adherens junctions without affecting the bloodtestis barrier integrity: an in vivo study using an androgen suppression model. Journal of Cellular Physiology 205 141-157.
Xia W, Mruk DD, Lee WM \& Cheng CY 2006 Differential interactions between transforming growth factor- $\beta 3 / \mathrm{T} \beta \mathrm{R} 1$, TAB1, and CD2AP disrupt blood-testis barrier and Sertoli-germ cell adhesion. Journal of Biological Chemistry 281 16799-16813.

Xiao K, Garner J, Buckley KM, Vincent PA, Chiasson CM, Dejana E, Faundez V \& Kowalczyk AP 2005 p-120-Catenin regulates clathrindependent endocytosis of VE-cadherin. Molecular Biology of the Cell $\mathbf{1 6}$ 5141-5151.

Yan HHN \& Cheng CY 2005 Blood-testis barrier dynamics are regulated by an engagement/disengagement mechanism between tight and adherens junctions via peripheral adaptors. PNAS 102 11722-11727.

Zhang J, Wong CH, Xia W, Mruk DD, Lee NPY, Lee WM \& Cheng CY 2005 Regulation of Sertoli-germ cell adherens junction dynamics via changes in protein-protein interactions of the $\mathrm{N}$-cadherin- $\beta$-catenin protein complex which are possibly mediated by c-Src and myotubularinrelated protein 2: an in vivo study using an androgen suppression model. Endocrinology 146 1268-1284.

Zwain IH \& Cheng CY 1994 Rat seminiferous tubular culture medium contains a biological factor that inhibits Leydig cell steroidogenesis: its purification and mechanism of action. Molecular and Cellular Endocrinology $104213-227$.

Received in final form 8 September 2006

Accepted 20 September 2006

Made available online as an Accepted Preprint

2 October 2006 